\title{
DBDB: A Database for Design Bibliography
}

\author{
Jorge Angeles, Marika Asimakopulos, David McKnight and Alexei Morozov \\ McGill University, Montreal, Canada \\ angeles@cim.mcgill.ca marika.asimakopulos@mcgill.ca \\ david.mcknight@mcgill.ca alexvit@cim.mcgill.ca
}

\begin{abstract}
Given the interdisciplinarity of engineering design, and the need of a swift access to an up-to-date bibliography on the subject, the production of a design database becomes an imperative and challenging task. This is how two designers of the McGill NSERC Chair in Design Engineering teamed up with two expert librarians, also of McGill University, in an attempt to produce a database with a search engine that caters to designers at large, with special emphasis on engineers.

The Design Bibliography Database aims at helping engineering designers, and designers at large to some extent, find bibliography items on specific topics of their multidiscipline. The first task to face is how to order the extremely rich literature on the subject. The bibliography database is currently being developed under the DBDB Project, as reported here.
\end{abstract}

\section{Introduction}

As envisioned, the DBDB will be a dynamic, selfarchiving bibliographic resource which will provide access to past, current and future references to the field of Design. An online submission form will allow researches to add either their work or newly discovered bibliography sources to the database. The most important aspects of the database are the data model, information architecture, metadata, subject access and information retrieval.

We start by noticing that design is used in English to indicate $(i)$ the process, $(i i)$ the object and (iii) the object representation. We are thus building a database upon the premise that these three items are the major branches of the search tree that we are devising to support our search engine. The three branches are outlined below.

\section{The Design Process}

A major activity in design research is the modelling of the process itself, which is tantamount to attempting a modelling of the thinking process, not a trivial task by any means.

Various models of the design process exist in the literature. One of these, that we can use as a suitable example, is due to French [1], who divides the process into two parts, (i) stages/descriptions and (ii) activities. The process is represented as a flow diagram, in which stages or descriptions are included in circles, while activities in rectangles. In this model, the process starts with a need and ends with "working drawings." Inbetween, we have a sequence, starting by the analysis of the problem, an activity, followed by the statement of the problem, a stage. Once the problem has been formulated, in design engineering terms, we suppose, as opposed to "client-needs" terms, the activity leading to the conceptual design follows. Out of this comes (come) the "selected scheme(s)," apparently a description. Then comes the "embodiment of scheme(s)," i.e., of the scheme(s) selected in the previous part. The embodiment is then followed by the "detailing" of the designed object, also an activity.

However, the design process is recognized as being anything but a one-way street. Two feedback loops are thus included in French's model: One at the conceptual design level, in which a revision may indicate that the problem needs further analysis, and hence, the designer or the design team must return to the first activity. A second loop arises at the embodiment level, at which the designer may realize that either a revision of the conceptual design is needed, or even a revision of the problem analysis is warranted.

The foregoing model contemplates the design process as a consultant's activity, in which a consultant - an individual or a company - participates in a project within an organization, to either develop a new product or improve an existing one. The model does not contemplate the prototyping aspects - usually outside of the scope of the consultant's activities - that lead to the realization of the design motivated by the client's need. Prototyping is needed when either an innovative product is under design or when an improvement on an existing design is planned that will affect thousands or millions 
of produced objects. Prototype tests may bring about various feedback loops in turn.

Now, in identifying the various disciplines that come into play in French's model, we find that the client is not necessarily a technical person by training. The client may come from a culture where verbal communication is more frequent than pictorial communication. The client's needs are usually fuzzy, the role of the designer being to interpret those needs in her or his own terms. We can thus readily identify here a keyword: fuzzy reasoning or fuzzy logic, which require techniques outside of the analytical disciplines found most frequently in engineering. The statement of the problem leading to the conceptual design brings about psychology issues, that sometimes have to do with individual or cultural barriers [2]. What is at stake in this part of the design process is the ability of the designer to generate alternatives and to do so by connecting situations and knowledge from the most diverse contexts. Hence, the psychology literature and the literature on idea generation, such as brainstorming techniques and synectics, are essential to the subject.

Reuleaux (1829-1905) is credited with the first attempt to create a tool that would allow the mechanism designer to generate alternatives, and hence, choose the best one [3]. The tool proposed by Reuleaux is domainspecific, but his idea that a syntax could be used to generate alternatives is not. The same concept can be used in other domains. Probably the reason why Reuleaux did not take his idea further is the lack of computational tools during his time. A current research stream focuses on the development of grammars to help the designer generate alternatives. Hence the need to access the rich literature on artificial intelligence (AI) that is pertinent to design and that studies techniques of communicating with the aid of formal languages.

A rich bibliography on the subject of idea generation exists in the German literature, not all of which is available in English. For example [4] put forth a concept under which engineering design can be regarded as a science not too different from physics, but his Methodisches Konstruieren is not available in English. Better known within the English-speaking design community is the work of Beitz [5], [6], [7], who proposed a systematic method of generating solutions to design problems. The foregoing works are paradigms of what we could call the German School of design engineering.

The level of the design process concerned with the selection of alternatives, leading to one or various solutions, requires domain-specific knowledge that falls into the realm of the analytical engineering disciplines: circuit theory; fluid mechanics; heat transfer; mechanism analysis; strength of materials; structural analysis; unit processes; and so on. The design bibliography need not include domain-specific entries, which are well doc- umented in specialized databases.

Detailing requires knowledge of domain-specific disciplines as well, but it also calls for skills that are proper of design engineering, such as the production of manufacturing drawings or circuit layouts. These topics are discussed below under Design Representation.

\section{The Design Object}

The design of an object intended to satisfy a need has been both extensively and intensively researched. The main issue here is the identification of criteria allowing the designer to choose among various alternatives, those generated at the conceptual-design level, the one that best meets the client's needs. The challenge is to find those criteria independent of the discipline, along with a criteria defining what "best" means. That is, the criteria must be valid regardless of whether the object under design is the "Confederation Bridge" or a "Wheatstone bridge," a "coffee filter" or a "low-pass filter."

Although the search for universally applicable design criteria, or design principles, as these are sometimes referred to, is domain-independent, most of the work on the subject has been originated by mechanical engineers.

Besides the German School, that is also pertinent to this part of the search tree, we have the two main streams in North America, robust design [8] and axiomatic design [9].

Axiomatic design and robust design exhibit a lot of common ground. In a deep analysis, both postulate that the designer should aim at the design with the minimum complexity. Which brings about one more issue that is of a philosophical nature, but that has been left aside by design researchers. The topic of complexity is well documented in the specialized literature [10], [11], [12].

\section{The Design Representation}

This topic has been recognized to be a key issue in design engineering [13]. Design representation is necessary to communicate among members of the design team, sometimes widespread around the world, to communicate with the client and, last but not least, to communicate with the machine shop, to communicate with the machine itself.

Representation is in itself a branch of philosophy, and hence, some works in the area of epistemology are pertinent to the design bibliography database as well. More to the mundane aspects of representation, issues around visual thinking are of the utmost importance [14].

Design representation has been lumped traditionally in the design curriculum under labels such as Graphics or Engineering Graphics, sometimes as Computer Graphics, to emphasize a modern twist of the subject [15]. Graphics courses used to stress the art of draw- 
ing to its minute details, such as how to sharpen the pencil, and how to use the drafting instruments. A description would be included of all possible instruments: the drafting machine; the $45^{\circ}$ and $30^{\circ}-60^{\circ}$ triangles; the protractor; the compass; the templates; the scales, while making a distinction between architect's and engineer's scales; the irregular curves; the splines; and so on. An important component of such a course used to be $D e$ scriptive Geometry, now rendered obsolete by drafting software. Indeed, the origins of Descriptive Geometry can be traced back to 1642, the date of publication of Mathurin Jousse's Les secrets de l'architecture [16]. The new subject was formalized by Gaspard Monge circa 1784, as documented by Hachette [17]. While Descriptive Geometry is now virtualy eliminated from the engineering curriculum, the subject played an important role in the development of engineering, to the point that, when Monge first introduced the concept at École Polytechnique in Paris, the French military decided to classify it as a military secret.

Literature on Descriptive Geometry and the old art of engineering drawing should be of interest to educators and scholars working in design research, and will be given a place within the DBDB.

\section{Existing Bibliography Sources}

The bibliography that inspired this project is found in [18], which represents the first attempt to compile the vast design bibliography of the time. One valuable source to cite here is the book by Hubka and Eder [19], with 465 bibliographic entries.

\section{DBDB Digital Library}

The DBDB has been conceived as a dynamic, multilingual, self-archiving utility to support research in the field of Design. The database will provide a snap-shot of the retrospective literature on the subject which is drawn from Siddall's unpublished comprehensive bibliography, References on Mechanical Design [18] and the extensive bibliography published in Hubka and Eder's Design Science [19]. It is noteworthy that, while Canada has been recognized as paying little attention to design, two designers who played a key role in the production of those bibliographies, Siddall and Eder, are associated with Canadian institutions.

At the same time that the DBDB captures the past literature, researchers in the field of design will be able to dynamically self-archive bibliographic information; this information will be accessible to researchers around the world. The subject of design will be treated mainly from the point of view of engineering, while including urban planning, architecture and other related domains.

At this stage, the DBDB Project is not envisioned to serve as a document repository. Rather, it will serve the bibliographic needs of the design community. Therefore, contributors will not be required to upload electronic copies of pre-prints, journal articles, or conference papers. However, when possible, contributors will be asked to provide hypertext links to documents that may exist on their own institutional servers.

Although commercial indexing databases, like Compendex and INSPEC serve as the most important resources in the field for monitoring the literature, the DBDB will provide subject focus that will draw upon the commercial databases for content, but also include a listing of other publication types such as preprints, websites, etc. that may not be included in Compendex or INSPEC.

The database and website is being developed by the McGill University Library's Digital Collections Program and a subject specialist Librarian in the Schulich Library of Science and Engineering, with the additional support of a graduate student in the Graduate School of Library and Information Science.

The DBDB Project consists of five elements:

- Data Conversion

- Data Model

- Search Engine

- Website Design

- Maintenance

We will elaborate below on these items.

\section{Data Conversion}

The first step in this project involved the capture of [18] and [19] bibliographies. The former was scanned, then processed using optical character recognition (OCR) software. After the OCR process, the text was edited and the entries were prepared for importation into the DBDB. The latter was taken from a MS Word document available online, by means of a link provided by [20], a key actor of the Canadian Design Engineering Network. In both cases bibliography entries were reviewed to determine which ones should be excluded from the database, either because they were deemed too general or because they were references to commercial and unpublished sources that were beyond the scope of the DBDB.

\section{Data Model}

A relational database has been adopted for the project and the project team is using the widely available opensource database program: MYSQL. We have developed a bibliographic data model, which includes the following elements: 


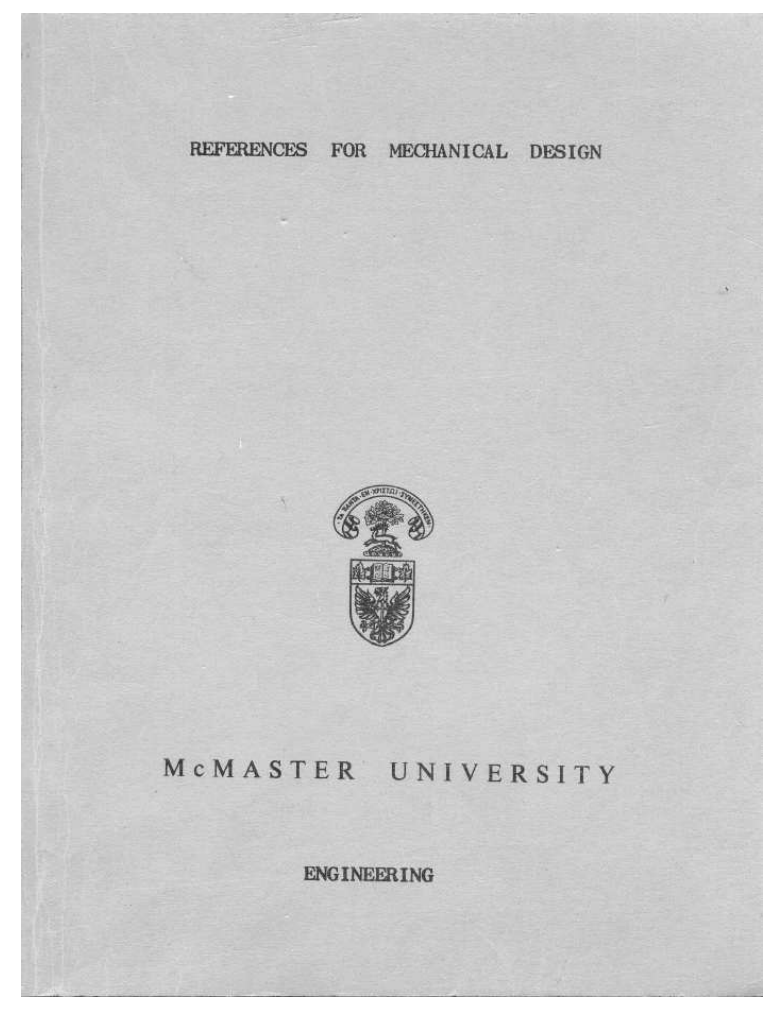

(a)

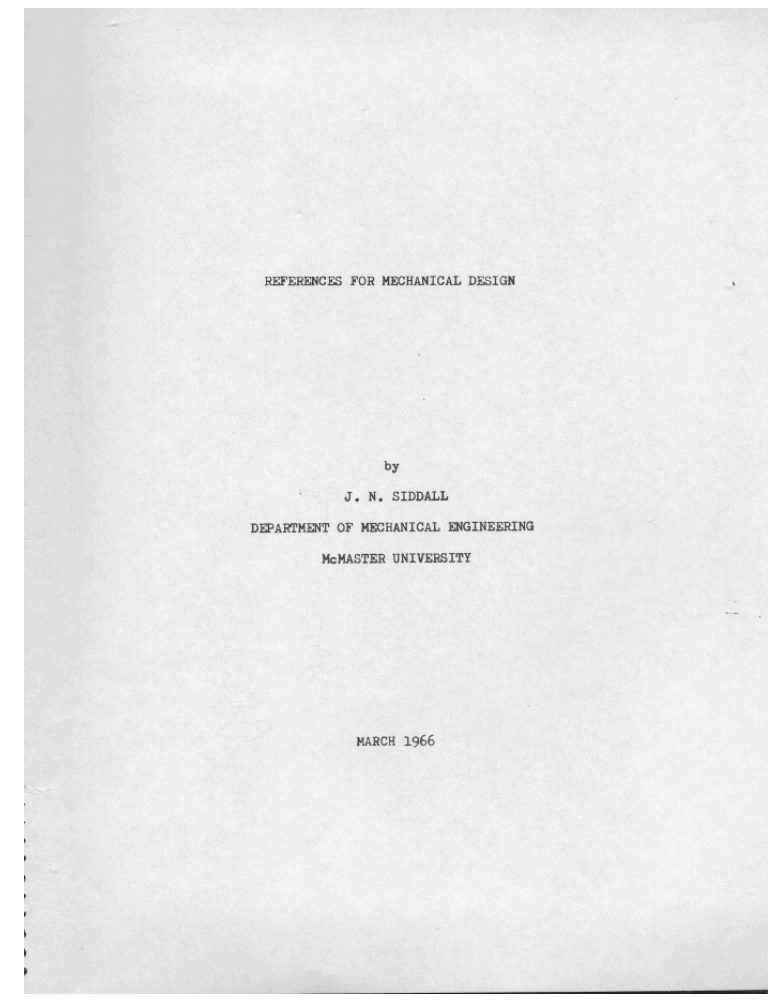

(b)

Figure 1: The McMaster book on Design Bibliography: (a) Cover; (b) Title page.

- Author(s)

- Publication Data (Title, Source, Year)

- Abstract

- Language

- Document Types (23)

- Keywords

- Descriptors

- Reference

- Notes

- External Links

- Institutional Affiliation

- Contact Information

Because the DBDB was conceived as a self-archiving tool, the only issue that adds some complexity to the process is the assigning of subject descriptors. We believe that subject descriptors are one of the critical tools for searching and retrieving relevant entries in the database. A controlled vocabulary list will be created and based upon the descriptors used in Compendex and INSPEC.
Entries imported from [18] and [19] bibliographies will be assigned subject headings. For each new entry that is uploaded, authors will select the appropriate terms from the subject authority list. However, to insure accuracy, each new item will be edited and subject terms will be validated. To insure the integrity of the database, elements such as author, publication data and subject will follow prescribed input methods and authority lists will be implemented to insure that all data are normalized for the purpose of accuracy and ease of searching and retrieval.

In the interest of data-sharing, the database model will be OAI (Open Archive Initiative)-compliant, thus enabling the harvesting of DBDB metadata for inclusion in other bibliographic repositories distributed throughout the world.

\section{Search Engine}

Adopting a relational database model will facilitate three levels of searching the contents of the database: browse; keyword; and advanced searching. In browse mode, users can quickly search a prescribed list of authors, titles or subjects. Keyword-searching will allow users to search for keywords in selected fields: author, title, publication data, abstract, keywords, AND descriptors. Advanced search will support Boolean searching and field-specific searching, for example, by author, doc- 
ument types, subject and date fields.

\section{Website Design}

Simple in design, the DBDB website will support three basic functions. The first is the bibliographic database for use by researchers in the field, which will form the primary content source for the site. The second function will be the uploading templates that will enable a contributor to enter a new record into the system. Finally, the third function of the site will be the search and retrieval pages, which will display the results.

\section{Maintenance}

One of the challenges of this project will be the ongoing maintenance and upkeep of the DBDB. From the librarian's perspective, it is essential that new entries uploaded into the database be edited for accuracy to eliminate data-entry errors. The second concern is the assignment of subject headings. For many, subjectsearching may seem redundant in the age of keywordsearching. By subscribing to subject headings each item in the database can be quickly grouped with items of a similar kind, thus providing quickly the researcher with a list of items related to a specific topic of interest. It is expected that the project will continue to partner with the Schulich Library.

\section{Acknowledgements}

This project was made possible with the support of the Faculty of Engineering, McGill University, as motivated by NSERC, through its CDEN support. All authors have equally contributed, the order being alphabetical.

\section{References}

[1] French, M.E., 1992, Form, Structure and Mechanism, Macmillan, London.

[2] Adams, J., 1974, Conceptual Blockbusting, The Portable Stanford, Stanford Alumni Association, Stanford, CA.

[3] Moon, F., 2003, "Franz Reuleaux: Contributtions to the 19th century kinematics and theory of machines," Applied Mechanics Reviews, Vol. 58, No. 2, March, pp. 261-285.

[4] Rodenacker, W.G., 1976, Methodisches Konstruieren, Second Edition, Springer-Verlag, BerlinHeidelberg-New York.

[5] Pahl, G. and Beitz, W., 1977, Konstruktionslehre, Springer-Verlag, Berlin.
[6] Pahl, G. and Beitz, W., 1996, Engineering Design: A Systematic Approach, 2nd Edition, Wallace, K.M. (editor); Lessing, L., Bauert, F. and Wallace, K.M. (translators), Springer-Verlag, London.

[7] Wallace, K.M. and Blessing, L.T.M., 2000, "Observations on some German contributions to Engineering Design in memory of Professor Wolfgang Beitz," Research in Engineering Design, Vol. 12, pp. 2-7.

[8] Taguchi, G. (Genichi), 1993, Taguchi on Robust Technology Development. Bringing Quality Engineering Upstream, ASME Press, New York.

[9] Suh, N.P., 2001, Axiomatic Design. Advances and Applications, Oxford University Press, Oxford.

[10] Delahaye, J.-P., 1999, Information, complexité et hasard, Éditions Hermès, Paris.

[11] Li, M. et Vitányi, P., 1997, An Introduction to Kolmogorov Complexity and Its Applications, Springer Verlag, Berlin.

[12] Wolfram, Stephen, 2002., "A New Kind of Science," Wolfram Media Inc., Champaign, IL.

[13] Dym, C. L., 1994, Engineering Design. A Synthesis of Views, Cambridge University Press, Cambridge, UK.

[14] Ferguson, E.S., 1977, "The mind's eye: Nonverbal thought in technology," Science, August, Vol. 197, No. 4306, pp. 827-836.

[15] Earle, J.H., 1999, Engineering Design Graphics. Autocad Release 14, Ninth Edition, AddisonWesley, Reading, MA.

[16] Asencheyev, B., 2002, Épures de Géométrie Descriptive. Concours d'Entrée à l'École Normale supérieure, Hermann, Paris.

[17] Hachette, J.-N.-P., 1828, Traité de géométrie descriptive, Corby, Paris.

[18] Siddall, J.N., 1966, References for Mechanical Design, Department of Mechanical Engineering, McMaster University, Hamilton, ON.

[19] Hubka, V. and Eder, W., 1996, Design Science, Springer-Verlag, London. 
[20] Salustri, F., 2003, Personal Communication, Broadcast electronically to all CDEN "champions", email message of September 04, 2003. 